\title{
SISTEM PENDUKUNG KEPUTUSAN KELAYAKAN PENERIMA SUBSIDI KEPEMILIKAN RUMAH MENGGUNAKAN ADAPTIVE NEURO-FUZZY INFERENCE SYSTEM
}

\author{
Barda Hudaya \\ Program Studi Informatika, Universitas Indraprasta PGRI \\ barda.hudaya@unindra.ac.id
}

\begin{abstract}
Abstrak
Perkembangan dunia Teknologi Informasi yang begitu cepat menyebabkan teknologi yang baru saja menjadi trend sudah menjadi barang usang dalam waktu yang singkat. sehingga keberadaan informasi yang akurat, cepat dan terpercaya sangat dibutuhkan dalam berbagai aspek kehidupan. Berbekal dari permasalahan yang timbul dari penelitian terdahulu yaitu akibat dari tidak diterapkannya aturan pemerintah dengan benar sehingga kepemilikan Rumah Siap Huni (RSH) ini kurang tepat sasaran untuk itulah penelitian ini dilakukan agar dapat membantu pihak pengembang mengambil keputusan menentukan kelayakan penerima subsidi kepemilikan Rumah Siap Huni, layak atau tidak sesuai dengan yang dipersyaratkan penerima hibah dari masyarakat berpenghasilan rendah. Serta dengan kriteria-kriteria yang digunakan untuk membantu pihak pengembang atau developer menentukan kelayakan penerima subsidi kepemilikan Rumah Siap Huni (RSH) dengan menerapkan metode ANFIS didalam pengembangan sistem pendukung keputusannya.
\end{abstract}

Kata Kunci : Masyarakat Berpenghasilan Rendah, Anfis, Rumah Siap Huni

\begin{abstract}
The development of the world of Information Technology is so fast that the technology that has just become a trend has become obsolete in a short time. so that the existence of accurate, fast and reliable information is needed in various aspects of life. Armed with the problems arising from previous research, that is the result of not implementing government regulations properly so that the ownership of RSH is not exactly the target for this research is carried out so that the developer can make decisions to determine the feasibility of recipients of House ownership ready, decent or inappropriate which is required by grant recipients from low-income communities. As well as with the criteria used to help the developer or developer determine the feasibility of the recipient of the Ready to Own House (RSH) subsidy by applying the ANFIS method in developing its decision support system.
\end{abstract}

Keywords: Low-Income Communities, Anfis, Houses Ready to Live

\section{PENDAHULUAN}

Perkembangan dunia Teknologi Informasi yang begitu cepat menyebabkan teknologi yang baru saja menjadi trend sudah menjadi barang usang dalam waktu yang singkat. sehingga keberadaan informasi yang akurat, cepat dan terpercaya sangat dibutuhkan dalam berbagai aspek kehidupan. Untuk itu peran komputer sebagai alat bantu untuk mendapatkan informasi menjadi sangat penting. Salah satu pemanfaatannya adalah sebagai alat pendukung pengambil keputusan untuk memberikan solusi terhadap satu permasalahan yang ada. Kebutuhan teknologi dan informasi ini juga memberikan pengaruh yang besar terhadap kemajuan infrastruktur khususnya bidang properti dan perumahan. Rumah merupakan suatu hal yang sangat penting bagi manusia, rumah bersih, dan layak untuk dihuni menjadi dambaan bagi kita semua.

Berdasarkan Undang-Undang Nomor 1 Tahun 2011 [1], tentang perumahan dan kawasan permukiman pada pasal 1 ayat 24 dinyatakan bahwa Masyarakat Berpenghasilan Rendah yang selanjutnya di singkat dengan MBR adalah masyarakat yang mempunyai keterbatasan daya beli 
sehingga perlu mendapat dukungan pemerintah untuk memperoleh rumah. Dalam upaya pemenuhan akan kebutuhan tempat tinggal yang layak, pemerintah telah menggalakan satu program untuk menyediakan rumah bersubsidi dalam bentuk rumah siap huni berupa rumah sederhana sehat dan rumah susun, juga di ikuti dengan sistem pembiayaan perumahan yang mudah untuk Masyarakat Berpenghasilan Rendah (MBR). Program ini dinamakan Program Gerakan Nasional Pembangunan Sejuta Rumah (GN-PSR).

Berbekal dari permasalahan yang timbul dari penelitian terdahulu yaitu akibat dari tidak diterapkannya aturan pemerintah dengan benar sehingga kepemilikan RSH ini kurang tepat sasaran untuk itulah penelitian ini dilakukan agar dapat membantu pihak pengembang mengambil keputusan menetukan kelayakan penerima subsidi kepemilikan Rumah Siap Huni, layak atau tidak sesuai dengan yang dipersyaratkan penerima hibah dari masyarakat berpenghasilan rendah.

Tujuan dari penelitian ini adalah membangun sebuah sistem pendukung keputusan dengan kriteria-kriteria yang digunakan untuk membantu pihak pengembang atau developer menetukan kelayakan penerima subsidi kepemilikan Rumah Siap Huni (RSH) dengan menerapkan metode ANFIS didalam pengembangan sistem pendukung keputusannya.

\section{METODE PENELITIAN}

Tahapan penelitian yang pertama dilakukan adalah mengembangkan konsep penelitian (studi lapangan dan studi pustaka), perencanaan penelitian kemudian menentukan rancangan Sistem, implementasi dan pengujian.

Ruang lingkup dari penelitian ini adalah masyarakat berpenghasilan rendah (MBR) yang ingin mendapatkan rumah siap huni (RSH).
Ada beberapa Tools yang digunakan dalam penelitian ini, yang pertama adalah Adaptive Neuro-Fuzzy Inference System (ANFIS), yang merupakan gabungan dari Fuzzy dengan Jaringan Syaraf Tiruan (JST). Berbeda dengan Fuzzy, ANFIS membuat rule berdasarkan data yang di training lewat mekanisme yang mirip dengan JST dan jenis rule yang dilayani hanya yang bertipe TakagiSugeno-Kang (TSK), yang sekarang ini lebih kita kenal dengan nama sugeno saja. Metode ini diprakasai pada tahun 1985 dengan tujuan untuk memperoleh rule yang berasal dari hubungan masukan dan keluaran suatu system, prinsipnya antara lain:

$$
\text { If } x \text { is } A \text { and } y \text { is } B \text { then } z=f(x, y)
$$

Di mana A dan B merupakan set Fuzzy sedangkan $\mathrm{Z}$ merupakan fungsi dalam bentuk crips (bukan Fuzzy). Berbeda dengan FIS, pada ANFIS keberhasilan Sistem ditentukan oleh data yang menjadi sumber pembelajaran karena data yang dimasukkan ke editor ANFIS berupa matriks masukan dan target sekaligus [7].

Tools yang kedua adalah Matlab Toolbox, Pada MATLAB banyak terdapat fungsifungsi logika Fuzzy yang bisa digunakan dan membarikan fasilitas Graphical User Interface (GUI) untuk mempermudah membangun system Fuzzy setelah TOOLBOX FUZZY nya terinstal.

Ada 5 GUI tolls yang dapat digunakan untuk membangun, mengedit, dan mengobservasi Sistem penalaran Fuzzy yaitu [6] :

1) Fuzzy Inference System (FIS) Editor;

2) Membership Function Editor;

3) Rule Editor;

4) Rule Viewer;

5) Surface Viewer

Teori fuzzy logic adalah memetakan sebuah ruang input ke dalam ruang output dengan menggunakan IF - THEN rules. Pemetaan dilakukan dalam suatu FIS 
(Fuzzy Inference System), urutan membership function editor yang berfungsi untuk mengedit fungsi keanggotaan himpunan fuzzy untuk tiap variabel input dan output, urutan rule. FIS mengevaluasi semua rule secara simultan untuk menghasilkan kesimpulan [6].

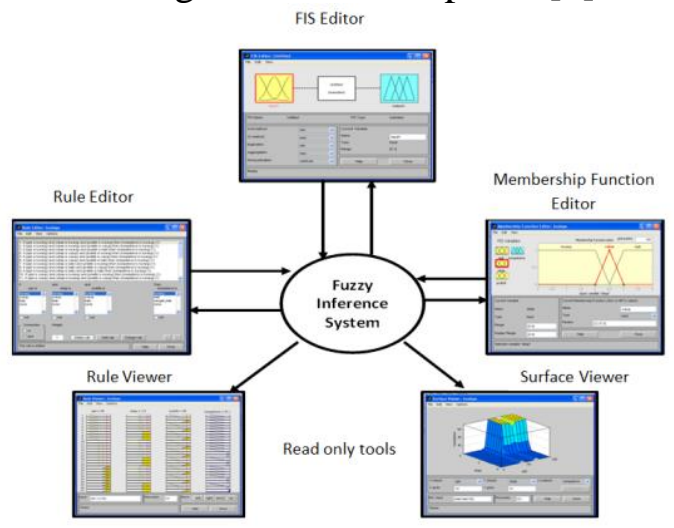
$\underset{\text { Sumber : [6] }}{\text { Gambar 1. Fuzzy Inee System }}$

Tools yang ketiga adalah Perangkat Lunak Matlab, Salah satu pemrograman dengan kemampuan tinggi dalam bidang komputasi adalah Matlab. Disamping itu kemampuan visualisasi dari perangkat lunak ini tergolong baik. Matlab memiliki kemampuan mengintegrasikan komputasi, visualisasi dan pemrograman. Dalam menvisualisasikan sebuah obyek, Matlab memiliki kemampuan merotasi obyek tanpa merubah programnya. Fitur utama Matlab dalam membuat visualisasi obyek adalah Guide.

GUI pada Matlab berfungsi sebagai penghubung antara Script Matlab yang tersimpan berupa M-File dan toolboxtoolbox Matlab seperti FIS, ANFIS, JST, Algoritma Genetik dan lain-lain [6].

\section{A. Pengumpulan Data}

Kajian literatur meliputi tinjauan pustaka dan tinjauan studi. Tinjauan pustaka adalah mengumpulkan beberapa data atau informasi tentang teori-teori yang berhubungan dengan penelitian ini, informasi tersebut dikumpulkan dari buku, jurnal, atau artikel didalam web, diantaranya mengenai perancangan dan dasar-dasar pembuatan system pendukung keputusan dengan metode ANFIS. Sedangkan tinjauan studi dilakukan untuk mengetahui gambaran menyeluruh terkait dengan penelitian yang akan dilakukan. Studi yang dilakukan untuk mengadopsi, mengembangkan dan memodifikasi kerangka teoritis yang pernah dilakukan.

\section{B. Sumber Data}

Adapun sumber data yang digunakan adalah data primer dan data sekunder. Data primer diambil langsung dari objek penelitian dalam hal ini berupa syaratsyarat dalam penetuan kelayakan penerima subsidi RSH. Sedangkan data sekunder diambil dari buku-buku perpustakaan, jurnal-jurnal ilmiah, paper, tesis dan informasi dari internet sebagai bagian landasan teori pelengkap dara primer yang lain.

\section{Tahap Analisis}

Tahap analisis dilakukan untuk menetapkan kebutuhan apa saja yang diperlukan dalam perangangan Sistem Pendukung Keputusan (SPK). Mengidentifikasi user pengguna, dan kebutuhan penunjang lainnya.

\section{Tahap Perancangan/ Desain}

Tahapan perancangan dilakukan untuk merancang Sistem Pendukung Keputusan (SPK) calon penerima hibah Rumah Siap Huni (RSH) dengan data dan hasil identifikasi dari calon pengguna sistem yang telah ditetapkan pada tahapan analisis.

\section{E. Tahap Simulasi}

Sistem yang telah dirancang nantinya akan disimulasikan untuk melihat apakah sistem sudah dapat berjalan dengan baik atau masih terdapat kesalahan atau bug agar dapat diperbaiki pada tahapan selanjutnya.

\section{F. Tahap Implementasi}

Tahapan implementasi adalah tahapan di mana sistem telah berjalan dengan baik 
setelah dilakukan perbaikan dari tahapan simulasi dan diimplementasikan langsung ke user.

\section{G. Tahap Evaluasi}

Tahapan ini dilakukan untuk menilai apakah Sistem Pendukung Keputusan (SPK) yang dibuat telah sesuai dengan yang diharapkan dan apakah user dapat beriteraksi secara cepat dengan Sistem Pendukung Keputusan (SPK) ini.

\section{HASIL DAN PEMBAHASAN}

Berikut adalah hasil dan pembahasan dari penelitian yang telah dilakukan:

\section{A. Pendefinisian Masalah}

Kelompok sasaran/ target penerima subsidi adalah keluarga/ rumah tangga termasuk perorangan baik yang berpenghasilan tetap maupun tidak tetap, belum pernah memiliki rumah, belum pernah menerima subsidi perumahan dan memiliki keterbatasan akses permodalan di lembaga keuangan formal publik atau swasta [3].

Kelompok sasaran yang memenuhi syarat mendapatkan subsidi yaitu memiliki persyaratan berikut:

1) Belum pernah memiliki rumah/ hunian.

2) Belum pernah menerima subsidi perumahan.

Tergolong MBR dan mempunyai penghasilan dari tempat bekerja/ usaha yang didasarkan atas gaji pokok atau pendapatan pokok per bulan,yang terbagi dalam 3 (tiga) kelompok sasaran, sebagaimana diatur dalam Pasal 2 Peraturan Menteri Negara Perumahan Rakyat Nomor 03/PERMEN/M/2007 tentang Pengadaan Perumahan dan Permukiman dengan Dukungan Fasilitas Subsidi Perumahan Melalui KPR Bersubsidi.

Ketepatan sasaran dapat dilihat dari data karakteristik pemilik rumah dengan melihat kecocokan pada ketentuan kelompok sasaran masyarakat berpenghasilan rendah, sebagai berikut [3]:

Tabel 1. Kelompok Sasaran Penerima Subsidi RSH

\begin{tabular}{ll}
\hline Kelompok Sasaran & Batasan Penghasilan (RP/Bulan) \\
\hline I & $1.700 .000 \leq$ penghasilan $\leq 2.500 .000$ \\
\hline II & $1.000 .000 \leq$ penghasilan $<1.700 .000$ \\
\hline III & penghasilan $<1.000 .000$ \\
\hline \multicolumn{2}{l}{ Sumber: Permenpera No.03/PERMEN/M/2007 }
\end{tabular}

Dengan pendefinisian yang telah diketahui diatas, maka dapat diambil kriteria dan variable seperti yang ditunjukan pada tabel 2 .

\section{B. Penentuan Membership Function (Jumlah Keanggotaan)}

Fungsi Keanggotaan (membership function) adalah suatu kurva yang menunjukan pemetaan titik-titik input data ke dalam nilai keanggotaannya [1].

Tabel 2. Variabel Penentuan Kelayakan Penerima Hibah RSH

\begin{tabular}{llc}
\hline No & \multicolumn{1}{c}{ Variabel } & Parameter \\
\hline 1. & Status Penghasilan & 2 \\
2. & Besar Penghasilan & 3 \\
3. & Kepemilikan Rumah & 2 \\
4. & Kepemilikan Kendaraan & 3 \\
5. & Status Pernikahan & 2 \\
\hline
\end{tabular}

Fungsi keanggotaan dalam penelitian ini adalah variabel dari data input, ada lima buah yaitu status penghasilan, besar penghasilan, kepemilikan rumah, kepemilikan kendaraan, dan status perkawinan. Selanjutnya tipe fungsi keanggotaannya akan diujicoba dengan fungsi keanggotaan segitiga (trimf), trapezium (trapmf), Gaussian (gasumf), dan lonceng (gbellmf) dan masing-masing fungsi keanggotaan tersebut akan dibandingkan masing-masing tingkat keakuratannya. 


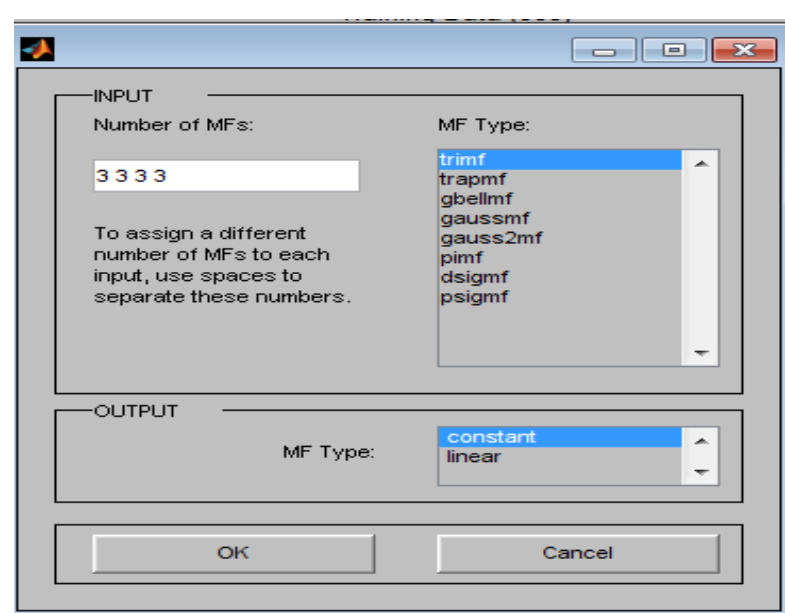

Gambar 2. Jumlah dan Jenis Tipe Keanggotaan

\section{Penerapan Matlab untuk pemrosesan Adaptive Neuro Fuzzy System}

Matlab telah terintegrasi dengan Fuzzy Logic Toolbox yang didalammnya terdapat ANFIS Editor GUI yang menunjukan fungsi kerja sebagai berikut:

1) Mengunggah (Loading), Memplot (ploting) dan membersihkan data.

2) Menggenerate atau mengunggah permulaan Struktur FIS

3) Melatih data FIS

4) Memvalidasi data FIS yang sudah dilatih.

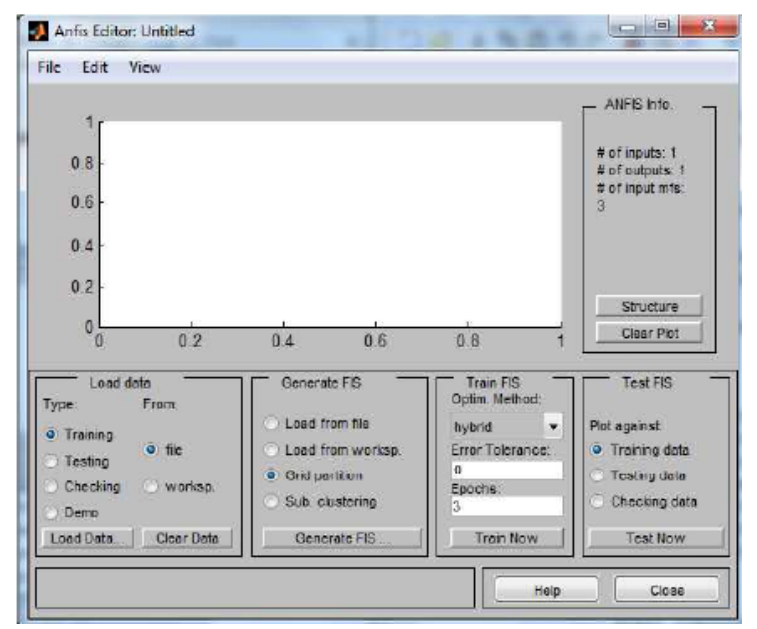

Gambar 3. Anfis Editor pada Matlab

\section{SIMPULAN}

Dari hasil analisis dan pengujian terhadap Sistem Pendukung Keputusan Kelayakan Penerima Subsidi Kepemilikan Rumah
Siap Huni (RSH) ini maka dapat disimpulkan bahwa:

1. Yang berhak menerima subsidi adalah keluarga/ rumah tangga termasuk perorangan baik yang berpenghasilan tetap maupun tidak tetap, belum pernah memiliki rumah, belum pernah menerima subsidi perumahan dan memiliki keterbatasan akses permodalan di lembaga keuangan formal publik atau swasta (Permenpera No.03/PERMEN/M/2007).

2. Kelompok tersebut memiliki persyaratan diantaranya belum pernah memiliki rumah, belum pernah menerima subsidi perumahan, dan termasuk kedalam masyarakat berpegnhasilan rendah (MBR).

3. Variabel penentuan kelayakan penerima hibah meliputi status penghasilan, besar penghasilan, kepemilikan rumah, kepemilikan kendaraan, dan status pernikahan.

\section{DAFTAR PUSTAKA}

[1] Kusumadewi, Sri., \& Hartati, Sri. Neuro-Fuzzy Integrasi Sistem Fuzzy Jaringan Syaraf. Yogyakarta: Graha Ilmu. 2010.

[2] Manturuk, Kim., Mark Lindblad and Roberto Quercia. Neighborhoods : A Longitudinal Analysis Homeownership and Civic Engagement in Low-Income Urban. Urban Affairs Review 2012 48: 731. 2012.

[3] Peraturan Menteri Negara Perumahan Rakyat Nomor: 03/Permen/M/2007 tentang Pengadaan Perumahan dan Permukiman Dengan Dukungan Fasilitas Subsidi Perumahan Melalui KPR Bersubsidi.

[4] Peraturan Menteri Negara Perumahan Rakyat Nomor 27 Tahun 2012 tentang Pengadaan Perumahan Melalui Kredit/Pembiayaan Pemilikan Rumah Sejahtera Dengan Dukungan Fasilitas Likuiditas Pembiayaan Perumahan. 
[5] Undang-Undang Republik Indonesia Nomor 1 Tahun 2011 Tentang Perumahan dan Kawasan Permukiman.
[6]Widodo, Prabowo Pudjo., Handayanto, Rahmadya Trias. Penerapan Soft Computing dengan Matlab. Bandung: Rekayasa Sains. 2012. 